\title{
Proteomic investigation of the effects of preimplantation factor on human embryo implantation
}

\author{
MIN YANG ${ }^{1}$, YIXUAN YANG ${ }^{1}$, SHA SHE$^{1}$ and SANGLIN LI ${ }^{2,3}$ \\ ${ }^{1}$ Department of Infectious Diseases, Institute for Viral Hepatitis, Key Laboratory of Molecular Biology for Infectious Diseases \\ (Ministry of Education); ${ }^{2}$ Department of Gynecology and Obstetrics; ${ }^{3}$ Reproductive Medical Center, \\ The Second Affiliated Hospital of Chongqing Medical University, Chongqing 400010, P.R. China
}

Received September 28, 2016; Accepted May 30, 2017

DOI: $10.3892 / \mathrm{mmr} .2017 .8338$

\begin{abstract}
Despite the use of adjuvant therapies, the cumulative proportion of live births remains at $\sim 40 \%$. Accumulating data show that low pregnancy rates, even in the presence of high fertility rates, are due to implantation failure. The present study aimed to identify and construct a profile of proteins that react with preimplantation factor (PIF) and to provide an understanding into the molecular mechanisms by which PIF promotes trophoblast invasion. Cytoplasmic proteins were immunoprecipitated with biotin-labeled synthetic PIF or intralipid and scrambled PIF (PIFscr). The protein profiles were analyzed using isobaric tags for relative and absolute quantification coupled with mass spectrometry. Immunoprecipitation and western blot analyses were used to assess the interactions between PIF and myosin heavy chain 10 (MYH10) and heat shock protein family D1. Small interfering RNA-based silencing was performed to examine the function of MYH10. In the results of the present study, 21 proteins were identified with interactions with PIF. The immunoprecipitation and western blot analyses revealed an interaction between PIF and MYH10. Silencing of the expression of MYH10 in HEC-1-B cells significantly attenuated cell migration and invasion capacities. These data support the conclusion that MYH10-mediated cell migration and invasion act in conjunction with PIF to promote the trophoblast invasion procedure.
\end{abstract}

\section{Introduction}

The decline in fertility in humans has been a medical concern for 25 years (1). The development of in vitro fertilization (IVF) has emerged as the most successful treatment for fertility problems. However, despite the use of adjuvant therapies,

Correspondence to: Dr Sanglin Li, Department of Gynecology and Obstetrics, The Second Affiliated Hospital of Chongqing Medical University, 76 Linjiang Road, Chongqing 400010, P.R. China E-mail:239808813@qq.com

Key words: preimplantation factor, myosin heavy chain 10 , implantation, invasion, interaction the cumulative percentage of live births remains at only $\sim 40 \%$ worldwide (2). The major factor limiting the success of IVF procedures is embryo implantation (3). Accumulating data has shown that low pregnancy rates, despite high fertility rates, are primarily due to implantation failure $(4,5)$. Each failure of in vitro fertilization has significant effects on the quality of life and mental wellbeing of patients, in addition to being a financial burden. Therefore, further investigations into the causes and mechanisms of implantation failure are warranted.

Embryo implantation, which requires a viable blastocyst and uterine receptivity, involves a series of steps, including the interaction and invasion of the blastocyst to the endometrium. The cross-talk between the embryo and the endometrium is essential for successful implantation (2). As implantation is the result of interactions between the blastocyst and endometrium, it is considered that this process is initiated as soon as a chemical interaction is established between the embryo and endometrium. The interaction between the blastocyst and endometrium begins immediately following entry of the embryo into the endometrial cavity and prior to active penetration of the endometrium by the developing blastocyst (6). In this respect, it has been reported that embryo-specific signaling is present prior to the embryo entering the endometrial cavity and making intimate contact with the endometrium (7-10).

Preimplantation factor (PIF) is a unique peptide, which is secreted only by viable embryos. PIF is detected first in the early stages, and is present throughout the duration of pregnancy in several species of mammal, where it is expressed in the placenta $(11,12)$. It has been noted that synthetic PIF (sPIF), which replicates native PIF function, affects key processes in early pregnancy implantation, including modulating peripheral immune cells, contributing to the maternal adaptation to pregnancy, and creating a favorable immune environment shortly following fertilization (13). Of note, sPIF can exert a positive autocrine effect on trophoblast invasion, and the invasion of trophoblast cells is enhanced by exposure to sPIF (14). Therefore, PIF is considered to promote or rescue placental invasion and represents a significant advance in reproductive technology.

In the present study, isobaric tags for relative and absolute quantification (iTRAQ) technology, combined with liquid chromatography-electrospray ionization-tandem mass spectrometry (LCESI-MS/MS) analysis, were used to identify key 
proteins that react with PIF, and western blot analysis was used for confirmation of findings. Using these measurements, the present study aimed to develop a profile of PIF-reactive proteins, and provide valuable understanding and insight into the molecular mechanism underlying the effect of PIF on the promotion of trophoblast invasion.

\section{Materials and methods}

Reagents and antibodies. Eight-plex iTRAQ reagent kits were acquired from Applied Biosystems; Thermo Fisher Scientific, Inc. (Waltham, MA, USA). Monoclonal antibodies against human PIF (18-802-392017) were obtained from GenWay (San Diego, CA, USA) and polyclonal antibodies against GAPDH (ab9485), MYH10 (ab684), tubulin, $\beta 5$ class I (TUBB5; ab15568) and heat shock protein family D1 (HSPD1; ab46798) were purchased from Abcam (Cambridge, UK). MYH10-specific Stealth Select RNAi ${ }^{\mathrm{TM}}$ small interfering (si)RNA (NM_005964.3), Stealth RNAi ${ }^{\mathrm{TM}}$ Negative Control siRNA (cat. no. 12935-400) and Lipofectamine 2000 transfection reagent were obtained from Thermo Fisher Scientific, Inc. CytoSelect $^{\mathrm{TM}}$ 24-Well Cell Migration and Invasion Assay kits ( $8 \mu \mathrm{m}$, colorimetric format) were purchased from Cell Biolabs (San Diego, CA, USA).

Cell lines and tissues. The HTR-8/SVneo cell line was derived from an explant culture of human first-trimester placenta and was used in the present study (15). HTR-8/SVneo cells, HEK 293 cells (Sigma; Merck Millipore, Darmstadt, Germany) HEC-1-B cells (Shanghai Institute of Cell Biology, Shanghai, China) were cultured at $37^{\circ} \mathrm{C}$, under $5.0 \% \mathrm{CO}_{2}$, in RPMI-1640 medium (Nanjing KeyGen Biotech. Co. Ltd., Nanjing, China) containing 10\% FBS (Gibco; Thermo Fisher Scientific, Inc.) and $100 \mathrm{IU} / \mathrm{ml}$ of penicillin. A total of 20 male and 20 female Sprague-Dawley rats (7 weeks old, 200-250 g), obtained from the Animals Experiment Center of Chongqing Medical University, were housed under controlled conditions $\left(25 \pm 2^{\circ} \mathrm{C}\right.$, $60 \pm 10 \%$ relative humidity and 12 -h light/dark cycle) with free access to tap water and food throughout the experimental period. Following 1 week of acclimation on an American Institute of Nutrition-93G diet, the male rats were randomly allocated into two groups of 10 animals per group: Healthy control group, and experimental group, in which rats receiving sterilization by surgical ligation. The breeders were paired every evening between 3:00 and 5:00 p.m., and were separated every morning between 9:00 and 10:00 a.m., followed by vaginal plug checks. After 4 days, all rats were euthanized with sodium pentobarbital ( $1 \mathrm{mg} / \mathrm{kg}$ bodyweight i.p.), endometrial tissues were extracted and fixed for $24 \mathrm{~h}$ in $4 \%$ paraformaldehyde in $1 \mathrm{X}$ PBS at $4^{\circ} \mathrm{C}$. All tissues were frozen with liquid nitrogen and preserved at $-196^{\circ} \mathrm{C}$. All rats received humane care in accordance with the guidelines of the Animal Usage Committee of the Chongqing Medical University (Chongqing, China), which approved the study prior to commencement.

Peptide synthesis. The partial characterization and PIF assay information were as described previously (16). Synthetic PIF, the purity of which was documented using high-performance liquid chromatography and mass spectrometry as $95 \%$, was produced by Biosynthesis, Inc. (Lewisville, TX, USA).
Synthetic PIF (sPIF; MVRIKPGSANKPSDD), intralipid and scrambled PIF (PIFscr; GRVDPSNKSMPKDIA) and biotin-labeled ligands of $>95 \%$ purity were also generated.

Invasion assays. Invasion assays were performed using a Cell Invasion Assay kit (Cell Biolabs, Inc., Beijing, China), according to the manufacturer's protocol. The HTR-8/SVneo $(50,000)$ cells were resuspended in medium with PIF or PIFscr (100 ng/ml). As determined using trypan blue exclusion under a light micros'cope (CK40; Olympus Corporation, Tokyo, Japan), $\sim 1 \times 10^{5}$ viable HTR-8/SVneo cells were seeded into the upper chamber of a 24 -well plate with polycarbonate membrane inserts. The numbers of cells to invade through the ECM Matrix gel were determined using CyQuant GR fluorescent dye $(560 \mathrm{~nm})$.

Co-immunoprecipitation (CoIP) and iTRAQ labeling. The HEK293 cells were trypsinized and lysed in $500 \mu 1$ lysis buffer (Western blot and immunoprecipitation; Beyotime Institute of Biotechnology, Inc., Haimen, China) on ice for $20 \mathrm{~min}$. The cell lysates were centrifuged for $15 \mathrm{~min}$ at $17,949 \mathrm{x} \mathrm{g}$ and $4^{\circ} \mathrm{C}$ to remove debris. Subsequently, $1 \mathrm{mg}$ of lysates $(1 \mu \mathrm{g} / \mu \mathrm{l})$ was mixed with biotin-labeled synthetic PIF or PIFscr overnight at $4^{\circ} \mathrm{C}$, and then precleared with $50 \mu \mathrm{l}$ ulfo-NHS-SS-avidin protein A-Sepharose beads (Pierce; Thermo Fisher Scientific, Inc.) for $2 \mathrm{~h}$ at $4^{\circ} \mathrm{C}$. The beads were pelleted and washed three times with lysis buffer. The bound proteins were eluted in SDS sample buffer and quantified by 2D Quantification kit assay (GE Healthcare Life Sciences, Little Chalfont, UK) according to the manufacturer's protocol. Then $20 \mu \mathrm{g}$ protein per well was subjected to $10 \%$ SDS-PAGE and analyzed by immunoblotting. The eluted protein $(100 \mu \mathrm{g})$ was precipitated from each pooled group, dissolved in dissolution buffer, denatured with $2 \%$ SDS, cysteine blocked, digested with $2 \mu \mathrm{g}$ of sequencing grade modified trypsin, and labeled using iTRAQ reagents (PIF, 117 tag; PIFScr, 118 tag) provided with the iTRAQ kit (AB Sciex Analytical Instrument Trading Co., Shanghai, China; Fig. 1). For the parallel experiment, the same sample set was labeled with iTRAQ reagents 119 and 121, respectively (Fig. 1). The peptides from each sample set were mixed prior to subsequent analysis.

Peptide fractionation. The labeled peptides were fractionated by immobilized-pH-gradient isoelectric focusing (IPG-IEF), as previously described $(17,18)$. Briefly, the samples were dissolved in a Pharmalyte (GE Healthcare Life Sciences, Chalfont, UK) and urea solution, rehydrated on a pH 3-10 IPG strip, and subjected to IEF at $68 \mathrm{kV} / \mathrm{h}$ using an IPG phor system (GE Healthcare Life Sciences). The peptides were extracted from the gel using an acetonitrile (ACN) and formic acid solution (19). The fractions were lyophilized, and purified with SPE Discovery DSC-18 columns (Supelco, Inc., Bellefonte, PA, USA). The purified peptides were re-lyophilized and stored at $-20^{\circ} \mathrm{C}$ until use.

Mass spectrometry. The purified peptide fractions were reconstituted in solvent $\mathrm{A}$, comprising water/ACN (98:2 v/v) with $0.1 \%$ formic acid, and separated using a C18-PepMap column (Thermo Fisher Scientific, Inc.) with a solvent gradient of $2-100 \%$ Buffer B $(0.1 \%$ formic acid and $98 \%$ acetonitrile) in Buffer $\mathrm{A}$ at a flow rate of $0.3 \mu \mathrm{l} / \mathrm{min}$. The peptides were electrosprayed using a nanoelectrospray 


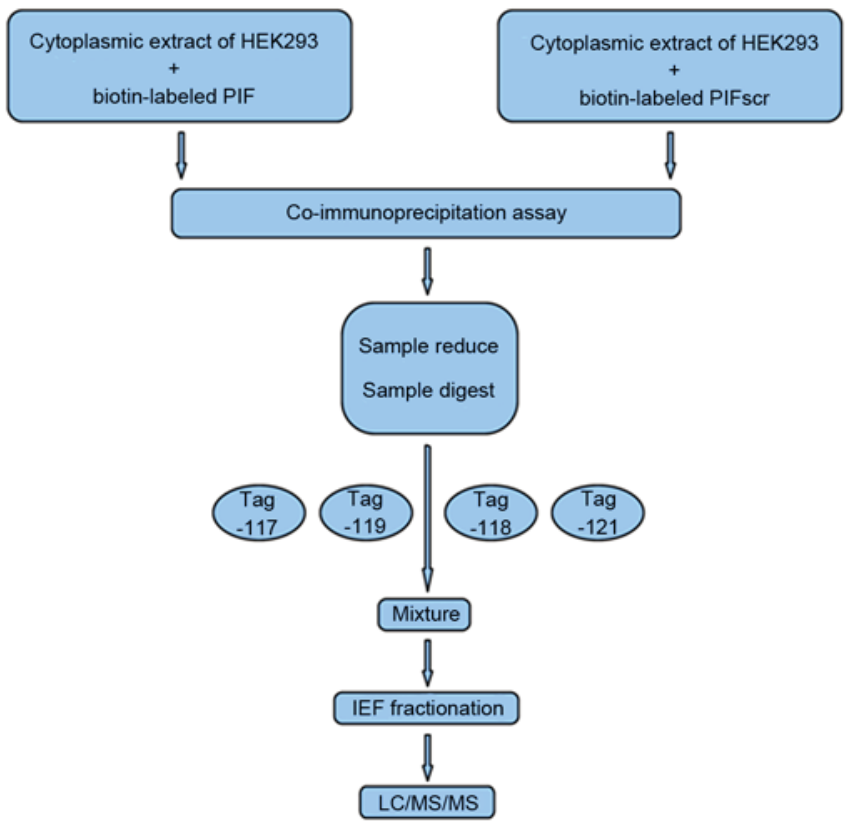

Figure 1. Flow chart of the isobaric tags for relative and absolute quantification proteomic approach. PIF, preimplantation factor; PIFScr, intralipid and scrambled PIF; IEF, isoelectric focusing; LC/MS/MS, liquid chromatography-tandem mass spectrometry.

ionization source at an ion spray voltage of 2,300 eV, and were analyzed using the NanoLC-ESI-Triple TOF 5600 system (AB Sciex Analytical Instrument Trading Co.). The mass spectrometer was set in the positive ion mode at a mass range of $300-1,800 \mathrm{~m} / \mathrm{z}$. The two most intensely charged peptides $>20$ counts were selected for tandem MS/MS at a dynamic exclusion of $30 \mathrm{sec}$ (19). Data were processed using ProteinPilot v2.0 (AB Sciex Analytical Instrument Trading Co.) and compared with the UniProt database (http://www. uniprot.org/). Cysteine modified by methane thiosulfate was specified as a fixed modification. Protein identification was based on a threshold protein score of $>1.3$. For quantitation, at least two unique peptides with $95 \%$ confidence and a P-value of $<0.05$ were required.

Bioinformatics analysis. The Gene Ontology was analyzed using the PANTHER classification system (http://www.pantherdb.org/) to determine biological processes, protein classes and molecular functions.

Western blot analysis. To validate the results of the proteomic analysis, the same sets of protein samples were subjected to immunoblot analyses. Each non-depleted sample was diluted 10 -fold with $10 \mathrm{mM}$ PBS. Two equal volumes of diluted samples $(20 \mu \mathrm{g})$ were separated by $10 \%$ SDS-PAGE, following which one volume was stained with Coomassie blue for protein loading determination and the other volume was transferred onto PVDF membranes for immunoblotting. The membranes were blocked in 5\% skim milk in Tris-buffered saline with Tween-20 at room temperature for $1 \mathrm{~h}$, and incubated with primary antibodies against GAPDH (1:2,500), PIF (1:200), MYH10 (1:2,000), TUBB5 $(1: 1,000)$ and HSPD1 $(1: 10,000)$ at $4^{\circ} \mathrm{C}$ overnight. The membranes were then incubated with HRP-conjugated goat anti-mouse immunoglobulin (Ig) G (sc-2005; 1:5,000) or goat anti-rabbit IgG (sc-2004; 1:5,000; both from Santa Cruz Biotechnology, Santa Cruz, CA, USA) at room temperature for $1 \mathrm{~h}$. Finally, the membranes were visualized using the ChemiDoc MP imaging system (Bio-Rad Laboratories, Inc., Hercules, CA, USA). The expression levels of PIF, MYH10 and HSPD1 in the endometrial tissues of rats were detected using the same immunoblotting procedure. The quantification of target proteins was determined using densitometry and normalized against GAPDH (Multi Sciences Biotech Co., Ltd., Hangzhou, China).

MYH10 siRNA transfection, Transwell and wound healing assays. When the cultures of HEC-1-B cells grown in $10 \mathrm{~cm}$ dishes with or without medium spiked with PIF or PIFscr (100 $\mathrm{ng} / \mathrm{ml}$ ) reached $95 \%$ confluence, they were transfected with $100 \mathrm{~nm}$ of MYH10-specific siRNA or a negative control siRNA (cat. no. 12935-400) using Lipofectamine 2000 (Invitrogen; Thermo Fisher Scientific, Inc.), according to the manufacturer's protocol. Cell viability was determined using a trypan blue exclusion assay, and only cells with $>95 \%$ viability were used for subsequent assays. The Transwell assays were performed as described previously (20). For the wound healing assays, the cells were cultured in 6-well plates until they reached $100 \%$ confluence. A $200-\mu 1$ pipette tip was used to scratch the cell monolayer, followed by washing with growth medium to remove debris. The resultant gap was monitored for up to $24 \mathrm{~h}$ under light microscopy (Eclipse 80i; Nikon Corporation, Tokyo, Japan).

Statistical analysis. Statistical analyses were performed using SPSS software v13.0 (SPSS Inc., Chicago, IL, USA). Quantitative variables are presented as the mean \pm standard deviation. Comparisons between groups were analyzed using Student's t-test or a Mann-Whitney U test. Qualitative variables are presented as counts and percentages, which were analyzed using the $\chi^{2}$ test. $\mathrm{P}<0.05$ was considered to indicate a statistically significant difference.

\section{Results}

PIF promotes HTR-8/Svneo cell invasion. To confirm the bioactivity of synthetic PIF in tumor cell motility, HTR-8/Svneo cells were resuspended in medium with PIF or PIFscr $(100 \mathrm{ng} / \mathrm{ml})$. A Matrigel invasion assay revealed that PIF increased the invasiveness of HTR-8/Svneo cells by $40-52 \%$, compared with the controls ( $\mathrm{P}<0.05$; Fig. 2).

MS identification and $i T R A Q$ quantification of aberrantly expressed proteins. To investigate the key proteins reacting with PIF, quantitative proteomics analysis using iTRAQ tags was performed. At least two peptides were used for quantification and protein identification. For Protein Pilot-based database searching and identification, the threshold [unused protscore (conf)] was set to achieve $95 \%$ confidence at $5 \%$ false discovery rate. The protein identification threshold, a ProtScore value $>1.3$, was used to attain a confidence of $95 \%$. When the proteins were classified as significantly regulated or not, an additional $>1.3(1 \times 1.3)$ or $<0.77$ (1/1.3)-fold cutoff was applied to all iTRAQ ratios to minimize false positives when determining whether proteins were overexpressed or 
underexpressed. This cutoff value was used as overall technical variation of data from the duplicate experiments was estimated $<30 \%$ (data not shown), and, in other investigations using the iTRAQ approach, this value has been widely used.

A total of 70 unique proteins were successfully identified by using at least two peptides (data not shown). A total of 21 proteins were differentially expressed in the PIF binding proteins of HEK 293 (Table I), of which 12 were upregulated and nine were downregulated in the PIF binding proteins, compared with the PIFscr proteins.

Gene Ontology analysis using PANTHER suggested that the majority of the differentially expressed proteins were enzymes or signaling molecules, followed by cell development regulators and cellular structure-related proteins (Fig. 3A and B).

Verification of aberrant expression of MYH10, TUBB5 and HSPDI. To determine the reliability of the ITRAQ analysis data, western blot and CoIP analyses were performed to confirm whether PIF interacts with MYH10, TUBB5 and HSPD1. As expected, MYH10, TUBB5 and HSPD1 were captured when using PIF as the bait protein (Fig. 4A-E).

Expression of MYH10, TUBB5 and HSPD1 in tissues. Western blot analysis was used to assess the expression of MYH10, TUBB5 and HSPD1 in the endometrial tissues of the experimental rats. The results indicated that MYH10, TUBB5 and HSPD1 were upregulated in the endometrial tissues of the pregnant rats (Fig. 5).

MYH1O knockdown attenuates HEC-1-B cell migration and invasion. To examine the role of MYH10 in tumor cell motility, protein expression was inhibited in HEC-1-B cell lines using RNA interference. The effective silencing with MYH10-specific siRNA was confirmed in the HEC-1-B cells using western blot analysis (Fig. 6A). Transfection of the HEC-1-B cells with MYH10-specific siRNA resulted in a $57-70 \%$ decrease in the ability to close scratch wounds, compared with the cells in the control siRNA group ( $\mathrm{P}<0.05$; Fig. 6B). The Matrigel invasion assay also revealed that MYH10-specific siRNAs decreased the invasiveness of HEC-1-B cells by $47-52 \%$, and the migration capacity of the HEC-1-B cells by $45-51 \%$, compared with the controls $(\mathrm{P}<0.05$ Fig. $6 \mathrm{C}$ and $\mathrm{D})$.

\section{Discussion}

Placental development is dependent on adequate invasion of the first-trimester trophoblast into the maternal decidua to sufficiently remodel maternal spiral arteries (21). By contrast, incomplete invasion has been implicated in a variety of adverse pregnancy outcomes, including fetal loss, fetal growth restriction and preeclampsia (22). The implantation of embryos into the maternal endometrium and placental formation with trophoblast invasion require a complex interplay of embryo-derived cellular signaling for establishing maternal immune receptivity, and for preparing the embryo itself to be suitable for invasion $(14,23)$. As an embryo-specific peptide, PIF is produced as early as the two-cell stage (11), and is understood to facilitate trophoblast invasion, eventually affecting placental development in the peri-implantation period (14).

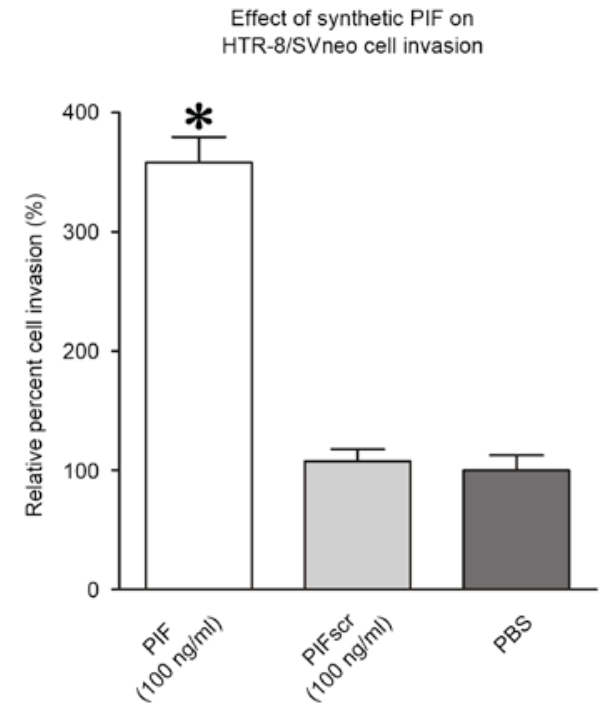

Figure 2. Effect of synthetic PIF on HTR-8/SVneo cell invasion. ${ }^{*} \mathrm{P}<0.05$ vs. PIFscr group. Bars indicate standard deviation. PIF, preimplantation factor; PIFScr, intralipid and scrambled PIF.
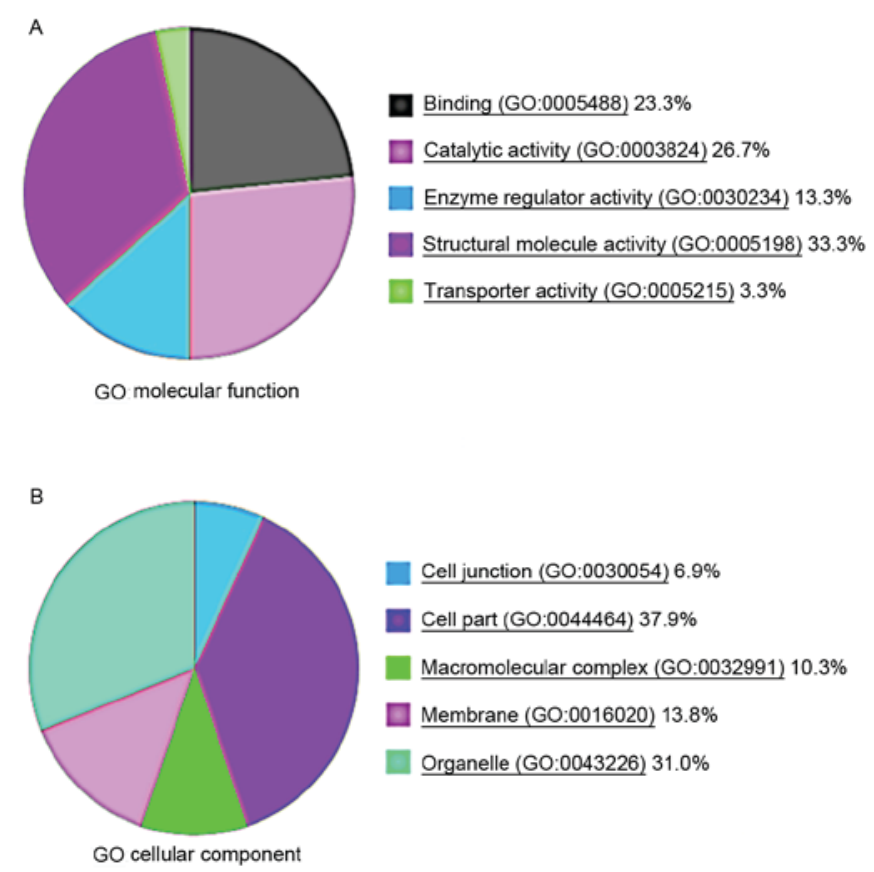

Figure 3. PIF-associated proteins categorized by (A) molecular function and (B) cellular component. PIF, preimplantation factor; GO, Gene Ontology.

In the present study, a protein profile was used to elucidate the molecular mechanism by which PIF promotes trophoblast invasion. Utilizing the iTRAQ proteomics approach, proteins interacting with PIF were identified. The use of immunoprecipitation confirmed that MYH10, TUBB5 and HSPD1 potentially interacted with PIF. Functional investigations indicated that MYH10 tended to act on the migration and invasion of HTR-8 trophoblast cells. The results of the present study revealed that the iTR AQ method for large-scale protein quantification was credible and amenable to high throughput investigations, and that the novel proteins uncovered may describe the PIF-relative interaction network in promoting 
Table I. List of differentially expressed proteins, identified using iTRAQ analysis, between PIF and PIFscr binding of cytoplasmic extracts in HEK293 cells.

\begin{tabular}{|c|c|c|c|c|c|c|}
\hline $\mathrm{n}$ & Accession & $\begin{array}{c}\text { Gene } \\
\text { symbol }\end{array}$ & $\begin{array}{l}\text { Protein } \\
\text { name }\end{array}$ & $\begin{array}{l}\text { Peptides } \\
(95 \%)\end{array}$ & $\begin{array}{l}\text { Cytoplasmic extract of } \\
\text { HEK293+biotin-labeled } \\
\text { PIF: cytoplasmic extract of } \\
\text { HEK293+biotin-labeled } \\
\text { PIFscr 117:118 (fold) }\end{array}$ & $\begin{array}{l}\text { Cytoplasmic extract of } \\
\text { HEK293+biotin-labeled } \\
\text { PIF: cytoplasmic extract of } \\
\text { HEK293+biotin-labeled } \\
\text { PIFscr 119:121 (fold) }\end{array}$ \\
\hline 1 & P05067 & APP & $\begin{array}{l}\text { Amyloid } \beta A 4 \text { protein } \\
\text { isoform d }\end{array}$ & 5 & 67.0963 & 70.4693 \\
\hline 2 & O94832 & MYO1D & Myosin-Id & 27 & 4.8306 & 4.4463 \\
\hline 3 & P35580 & MYH10 & $\begin{array}{l}\text { Isoform } 1 \\
\text { of Myosin-10 }\end{array}$ & 741 & 4.1281 & 4.1305 \\
\hline 4 & Q12965 & MCM3AP & $\begin{array}{l}80 \mathrm{kDa} \\
\mathrm{MCM} 3 \text {-associated protein }\end{array}$ & 3 & 3.3729 & 2.6546 \\
\hline 5 & P68371 & TUBB2C & Tubulin $\beta-2 \mathrm{C}$ chain & 14 & 1.8707 & 2.4434 \\
\hline 6 & O00159 & MYO1C & Isoform 1 of myosin-Ic & 2 & 1.7865 & 2.0137 \\
\hline 7 & P67936 & TPM4 & $\begin{array}{l}\text { Isoform } 1 \text { of } \\
\text { tropomyosin } \alpha-4 \text { chain }\end{array}$ & 52 & 1.3062 & 1.6904 \\
\hline 8 & P07437 & TUBB & Tubulin $\beta$ chain & 13 & 2.1281 & 1.6444 \\
\hline 9 & P68363 & TUBA1B & Tubulin $\alpha-1 \mathrm{~B}$ chain & 11 & 1.7219 & 1.6144 \\
\hline 10 & Q9NYL9 & TMOD3 & Tropomodulin-3 & 13 & 1.5560 & 1.5704 \\
\hline 11 & P07195 & LDHB & $\begin{array}{l}\text { L-lactate } \\
\text { dehydrogenase B chain }\end{array}$ & 2 & 1.4450 & 1.4588 \\
\hline 12 & P06753 & TPM3 & $\begin{array}{l}\text { Isoform } 2 \text { of } \\
\text { tropomyosin } \alpha-3 \text { chain }\end{array}$ & 75 & 1.3428 & 1.3428 \\
\hline 13 & $\mathrm{P} 02533$ & KRT14 & $\begin{array}{l}\text { Keratin, type I } \\
\text { cytoskeletal } 14\end{array}$ & 7 & 0.5546 & 0.7112 \\
\hline 14 & P13645 & KRT10 & $\begin{array}{l}\text { Keratin, type I } \\
\text { cytoskeletal } 10\end{array}$ & 35 & 0.1393 & 0.6918 \\
\hline 15 & Q7Z406 & MYH14 & $\begin{array}{l}\text { Isoform } 1 \\
\text { of myosin-14 }\end{array}$ & 297 & 0.5105 & 0.6252 \\
\hline 16 & P08779 & KRT16 & $\begin{array}{l}\text { Keratin, type I } \\
\text { cytoskeletal } 16\end{array}$ & 7 & 0.4786 & 0.6026 \\
\hline 17 & P04264 & KRT1 & $\begin{array}{l}\text { Keratin, type II } \\
\text { cytoskeletal } 1\end{array}$ & 49 & 0.2051 & 0.5754 \\
\hline 18 & P35908 & KRT2 & $\begin{array}{l}\text { Keratin, type II } \\
\text { cytoskeletal } 2 \text { epidermal }\end{array}$ & 18 & 0.4699 & 0.5200 \\
\hline 19 & P08238 & HSP90AB1 & $\begin{array}{l}\text { Heat shock } \\
\text { protein HSP } 90-\beta\end{array}$ & 2 & 0.2489 & 0.1459 \\
\hline 20 & P02042 & HBD & Hemoglobin subunit $\delta$ & 6 & 0.5754 & 0.0738 \\
\hline 21 & P69905 & HBA2; HBA1 & Hemoglobin subunit $\alpha$ & 9 & 0.7586 & 0.0136 \\
\hline
\end{tabular}

${ }^{\mathrm{a}} 117: 118$ and 119:121 refer to the relative level of protein expression in PIF with respect to PIFscr. Statistical calculation for iTRAQ-based detection and relative quantification were calculated using the Paragon Algorithm of ProteinPilot software. iTRAQ, isobaric tags for relative and absolute quantification; PIF, preimplantation factor; PIFScr, intralipid and scrambled PIF.

trophoblast invasion, thus advancing the knowledge of its functional mechanism.

Certain aspects of the implantation process resemble tumor invasion, whereas the implantation process consists of a precisely controlled series of events. The initiation of implantation requires that the trophoblast attaches, via its apical plasma membrane, to the apical plasma membrane of the uterine epithelium. As apical plasma membranes of epithelia are usually non-adhesive, cells can express the mesenchymal/fibroblastoid phenotype to allow the cells to move individually, or express the epithelioid phenotype to migrate as sheets. The trophoblast of blastocysts alters its motility apparatus to accommodate the invasion process. Collective cell migration requires the dynamic reorganization of cell-cell junction complexes and associated cytoskeletal structures to allow cells to alter their positions without losing cell-cell contacts. The invasion of 
A

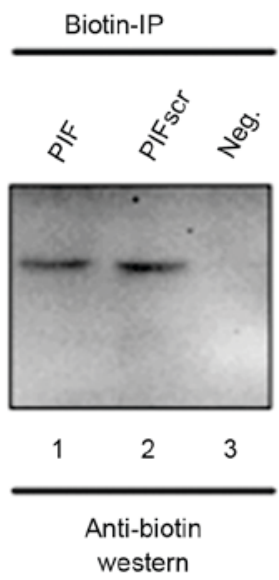

B

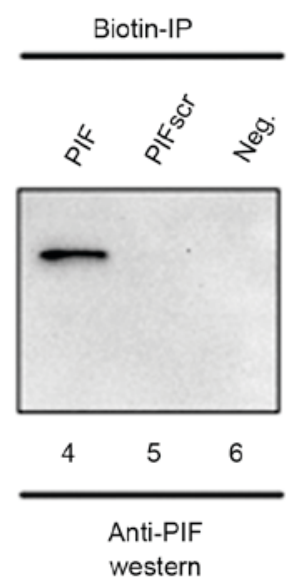

C

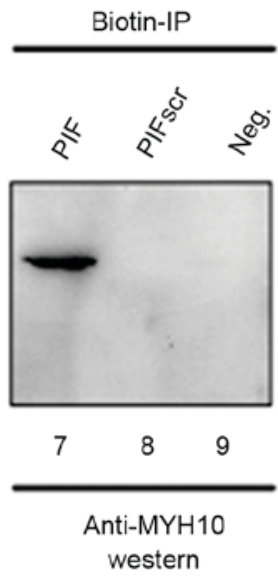

D

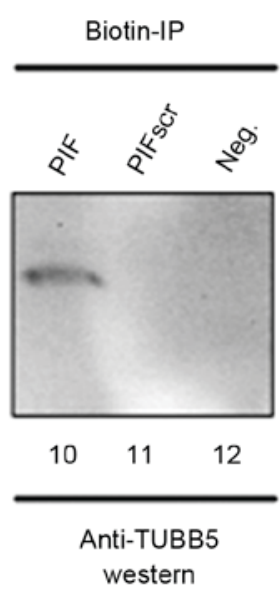

E

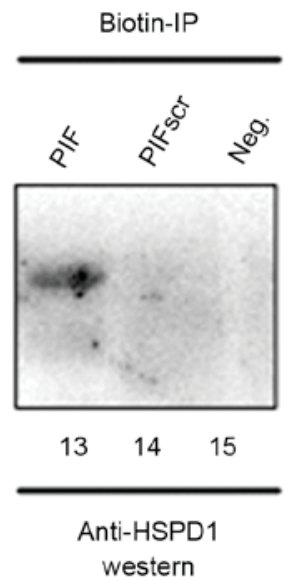

Figure 4. Biochemical purification and identification of PIF-associated protein factors. PIF protein complexes from cytoplasmic extracts of HEK293 cells were mixed with biotin-labeled PIF (lanes 1, 4, 7, 10 and 13) or PIFscr (lanes 2, 5, 8, 11 and 14). In lanes 3, 6, 9, 12 and 15, no biotin-labeled PIF or PIFscr was added. Anti-biotin IPs were analyzed using western blot analysis with (A) anti-biotin (lanes 1-3), (B) anti-PIF (lanes 4-6), (C) anti-MYH10 (lanes 7-9), (D) anti-TUBB5 (lanes 10-12) and (E) anti-HSPD1 (lanes 13-15). PIF, preimplantation factor; PIFScr, intralipid and scrambled PIF; IP, immunoprecipitate; MYH10, and myosin heavy chain 10; TUBB5, tubulin, $\beta 5$ class I; HSPD1, heat shock protein family D1; Neg., negative control.

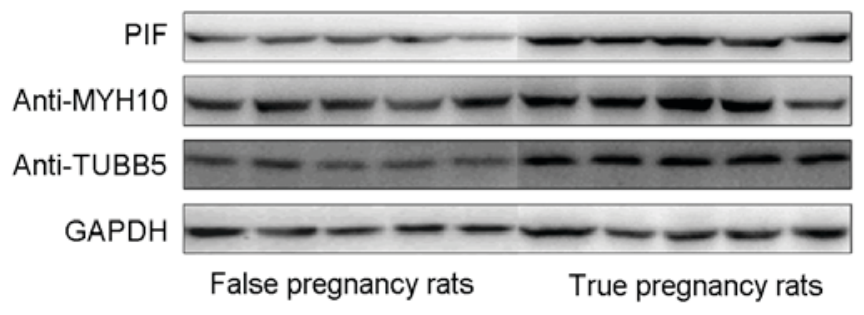

Figure 5. Representative western blots of the expression of PIF and MYH10 in decidual tissues from five cases of false pregnancy rats and true pregnancy rats. PIF and MYH10 were markedly upregulated in decidual tissues of the true pregnancy rats. PIF, preimplantation factor; MYH10, and myosin heavy chain 10; TUBB5, tubulin, $\beta 5$ class I.

trophoblast cells occurs through the stroma in a regulated manner by the remodeling of the extracellular matrix. A specialized submembrane filamentous network supports stable cell-cell binding between these cells (24). Myosin II is an actin-binding protein, which is central in the control of cell adhesion, cell migration and tissue architecture. Acting as an actin cytoskeleton, MYH10 regulates cell polarity, adhesion and migration. MYH10 can also affect cancer progression via the initial acquisition of malignant properties by normal cells, invasion of adjacent tissues and metastasis to distant sites $(25,26)$. These processes involve the dynamic remodeling of the actin cytoskeleton and the interaction of the cell with its environment. MYH10 facilitates protrusion formation via the generation of retrograde flow of actin in the lamellum, which is connected to the lamellipodium $(27,28)$. Inhibition of the activity of MYH10 with blebbistatin, or the genetic deletion of MYH10, markedly decreases the rate of actin retrograde flow in the lamellum $(27,28)$ and inhibits the coalescence of actin into proto-bundles at the lamellipodium-lamellum interface $(29,30)$, which increases protrusiveness. According to the role of MYH10 in regulating metastasis, actin cytoskeleton-mediated cell migration and invasion can support the PIF-induced promotion of trophoblast invasion.

The present study identified several potential molecules to assist in explaining the mechanism of PIF-mediated trophoblast invasion. Taken together, the interaction between PIF and MYH10 significantly enhanced the invasion and migration capabilities of HTR-8 trophoblast cells. These findings, coupled with 
A
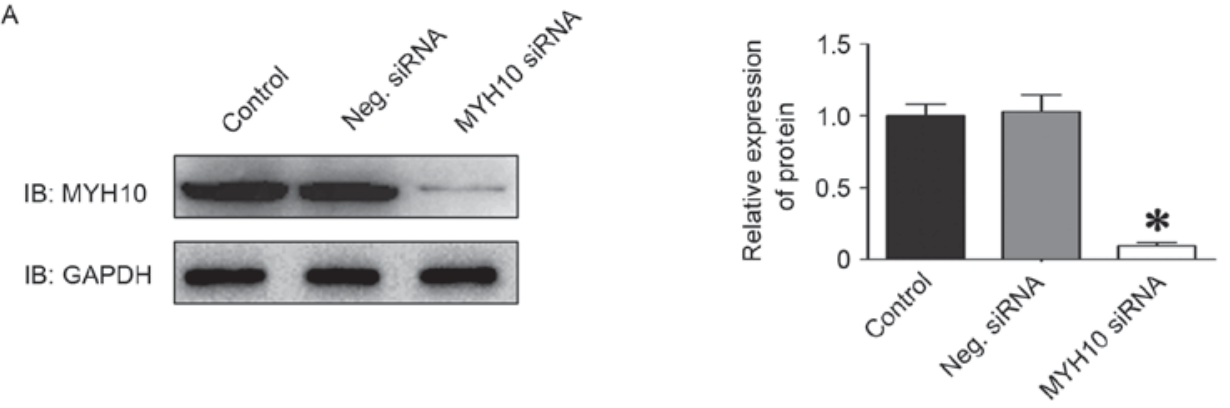

B

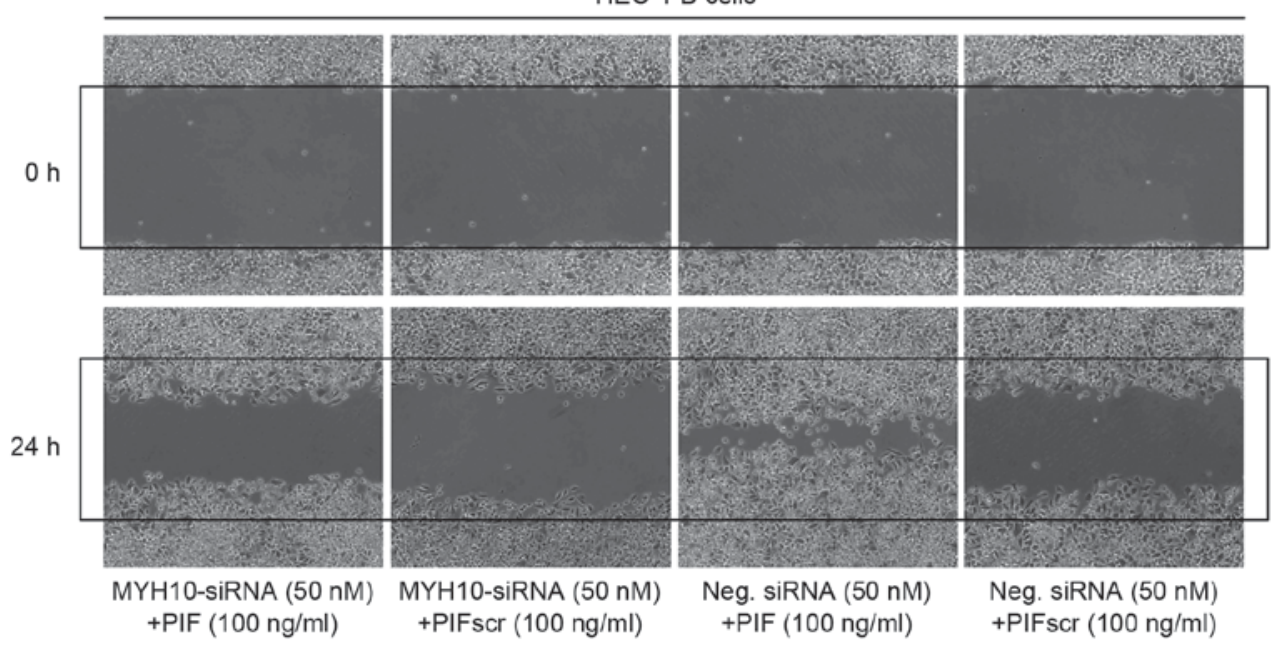

C

Role of MYH10 in PIF-induced invasion in HEC-1-B cells

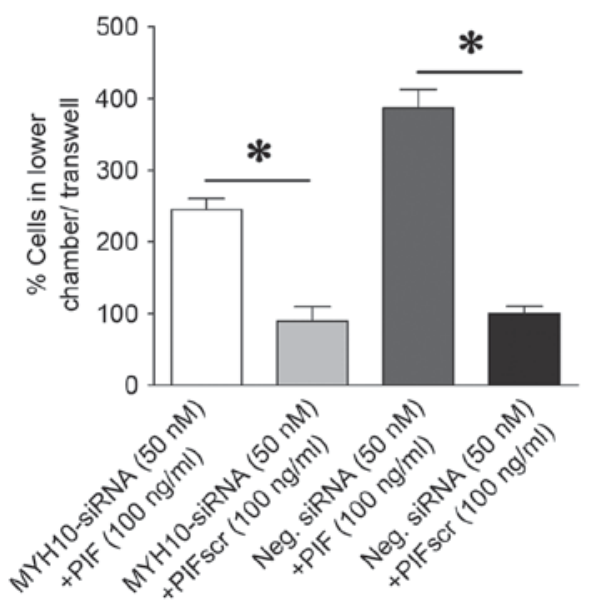

D

Role of MYH10 in PIF-induced migration in HEC-1-B cells

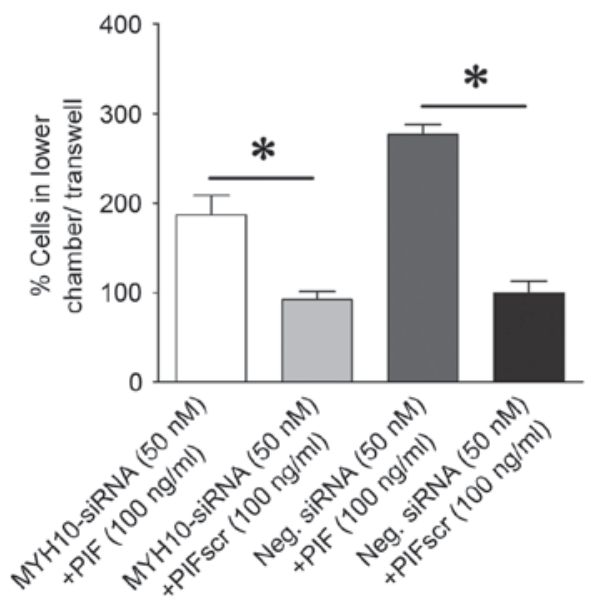

Figure 6. Role of MYH10 in PIF-induced invasion and migration of HEC-1-B cells. (A) Western blot analysis. "P<0.05 vs. Neg. siRNA group. Bars indicate standard deviation. (B) Wound healing assay. (C) Matrigel invasion assay. ${ }^{*} \mathrm{P}<0.05$ vs. PIFscr group. Bars indicate standard deviation. (D) Migration assay. ${ }^{*} \mathrm{P}<0.05$ vs. PIFscr group. Bars indicate standard deviation. PIF, preimplantation factor; PIFScr, intralipid and scrambled PIF; MYH10, and myosin heavy chain 10; siRNA, small interfering RNA; Neg. negative control.

the known embryonic effects of sPIF, suggest that this peptide requires investigation to promote or rescue placental invasion, and are a significant advance in reproductive technology.

\section{Acknowledgements}

The present study was supported by the grant from the National High Technology Research and Development
Program of China (863 Program; grant no. 2014AA022209), the Natural Science Foundation Project of CQ CSTC (grant no. 2012jjA10064), the Natural Science Foundation Project of CQ CSTC (grant no. 2013jcyj A 10060), the class General Financial Grant from the China Postdoctoral Science Foundation (grant no. 2012M511912), and the Chongqing Postgraduate Research Innovation Project (grant no. CYB15091). 


\section{References}

1. Carlsen E, Giwercman A, Keiding N and Skakkebaek NE: Evidence for decreasing quality of semen during past 50 years. BMJ 305: 609-613, 1992.

2. Zeyneloglu HB and Onalan G: Remedies for recurrent implantation failure. Semin Reprod Med 32: 297-305, 2014.

3. Kulak D, Jindal SK, Oh C, Morelli SS, Kratka S and McGovern PG: Reporting in vitro fertilization cycles to the society for assisted reproductive technology database: Where have all the cycles gone? Fertil Steril 105: 927-931, 2016.

4. Paulson RJ, Sauer MV and Lobo RA: Embryo implantation after human in vitro fertilization: Importance of endometrial receptivity. Fertil Steril 53: 870-874, 1990.

5. Margalioth EJ, Ben-Chetrit A, Gal M and Eldar-Geva T: Investigation and treatment of repeated implantation failure following IVF-ET. Hum Reprod 21: 3036-3043, 2006.

6. Tabibzadeh S and Babaknia A: The signals and molecular pathways involved in implantation, a symbiotic interaction between blastocyst and endometrium involving adhesion and tissue invasion. Hum Repro 10: 1579-1602, 1995.

7. Somerset DA, Zheng Y, Kilby MD, Sansom DM and Drayson MT: Normal human pregnancy is associated with an elevation in the immune suppressive CD25+ CD4+ regulatory T-cell subset. Immunology 112: 38-43, 2004.

8. Fuzzi B, Rizzo R, Criscuoli L, Noci I, Melchiorri L, Scarselli B, Bencini E, Menicucci A and Baricordi OR: HLA-G expression in early embryos is a fundamental prerequisite for the obtainment of pregnancy. Eur J Immunol 32: 311-315, 2002.

9. Cavanagh AC and Morton $\mathrm{H}$ : The purification of early-pregnancy factor to homogeneity from human platelets and identification as chaperonin 10. Eur J Biochem 222: 551-560, 1994.

10. Minhas BS, Ripps BA, Zhu YP, Kim HN, Burwinkel TH and Gleicher N: Platelet activating factor and conception. Am J Reprod Immunol 35: 267-271, 1996.

11. Roussev RG, Coulam CB and Barnea ER: Development and validation of an assay for measuring preimplantation factor (PIF) of embryonal origin. Am J Reprod Immunol 35: 281-287, 1996.

12. Barnea ER, Simon J, Levine SP, Coulam CB, Taliadouros GS and Leavis PC: Progress in characterization of pre-implantation factor in embryo cultures and in vivo. Am J Reprod Immunol 42: 95-99, 1999.

13. Stamatkin CW, Roussev RG, Stout M, Absalon-Medina V, Ramu S, Goodman C, Coulam CB, Gilbert RO, Godke RA and Barnea ER: PreImplantation Factor (PIF) correlates with early mammalian embryo development-bovine and murine models. Reprod Biol Endocrinol 9: 63, 2011.

14. Duzyj CM, Barnea ER, Li M, Huang SJ, Krikun G and Paidas MJ: Preimplantation factor promotes first trimester trophoblast invasion. Am J Obstet Gynecol 203: 402.e1-e4, 2010.

15. Jovanović $M$ and Vićovac L. Interleukin- 6 stimulates cell migration, invasion and integrin expression in HTR-8/SVneo cell line. Placenta 30: 320-328, 2009.

16. Barnea ER, Kirk D, Ramu S, Rivnay B, Roussev R and Paidas MJ: PreImplantation Factor (PIF) orchestrates systemic antiinflammatory response by immune cells: Effect on peripheral blood mononuclear cells. Am J Obstet Gynecol 207: 313.e1-11, 2012.
17. Yang Y, Lim SK, Choong LY, Lee H, Chen Y, Chong PK, Ashktorab H, Wang TT, Salto-Tellez M, Yeoh KG and Lim YP: Cathepsin $\mathrm{S}$ mediates gastric cancer cell migration and invasion via a putative network of metastasis-associated proteins. J Proteome Res 9: 4767-4778, 2010.

18. Tong SW, Yang YX, Hu HD, An X, Ye F, Hu P, Ren H, Li SL and Zhang DZ: Proteomic investigation of 5-fluorouracil resistance in a human hepatocellular carcinoma cell line. J Cell Biochem 113: 1671-1680, 2012.

19. Yang Y, Toy W, Choong LY, Hou P, Ashktorab H, Smoot DT, Smoot DT, Yeoh KG and Lim YP: Discovery of SLC3A2 cell membrane protein as a potential gastric cancer biomarker: Implications in molecular imaging. J Proteome Res 11: 5736-5747, 2012.

20. She S, Xiang Y, Yang M, Ding X, Liu X, Ma L, Liu Q, Liu B, Lu Z, Li S, et al: C-reactive protein is a biomarker of AFP-negative HBV-related hepatocellular carcinoma. Int J Oncol 47: 543-554, 2015.

21. Orsi NM and Tribe RM: Cytokine networks and the regulation of uterine function in pregnancy and parturition. J Neuroendocrinol 20: 462-469, 2008.

22. Lala PK and Chakraborty C: Factors regulating trophoblast migration and invasiveness: Possible derangements contributing to pre-eclampsia and fetal injury. Placenta 24: 575-587, 2003.

23. von Rango U: Fetal tolerance in human pregnancy-a crucial balance between acceptance and limitation of trophoblast invasion. Immunol Lett 115: 21-32, 2008.

24. Denker HW: Implantation: A cell biological paradox. J Exp Zool 266: 541-558, 1993.

25. Conti MA and Adelstein RS: Nonmuscle myosin II moves in new directions. J Cell Sci 121: 11-18, 2008.

26. Ouderkirk JL and Krendel M: Non-muscle myosins in tumor progression, cancer cell invasion, and metastasis. Cytoskeleton (Hoboken) 71: 447-463, 2014

27. Ponti A, Machacek M, Gupton SL, Waterman-Storer CM and Danuser G: Two distinct actin networks drive the protrusion of migrating cells. Science 305: 1782-1786, 2004.

28. Giannone G, Dubin-Thaler BJ, Rossier O, Cai Y, Chaga O, Jiang G, Beaver W, Döbereiner HG, Freund Y, Borisy G and Sheetz MP: Lamellipodial actin mechanically links myosin activity with adhesion-site formation. Cell 128: 561-575, 2007.

29. Anderson TW, Vaughan AN and Cramer LP: Retrograde flow and myosin II activity within the leading cell edge deliver F-actin to the lamella to seed the formation of graded polarity actomyosin II filament bundles in migrating fibroblasts. Mol Biol Cell 19: 5006-5018, 2008.

30. Nemethova M, Auinger S and Small JV: Building the actin cytoskeleton: Filopodia contribute to the construction of contractile bundles in the lamella. J Cell Biol 180: 1233-1244, 2008.

This work is licensed under a Creative Commons Attribution-NonCommercial-NoDerivatives 4.0 International (CC BY-NC-ND 4.0) License. 